\title{
A paleointensity test of the Geocentric Axial Dipole (GAD) hypothesis
}

\section{Veikkolainen, Toni Henri Kristian}

2017-04

\begin{abstract}
Veikkolainen, T H K, Heimpel , M , Evans , M E , Pesonen , L \& Korhonen, K 2017 , ' A paleointensity test of the Geocentric Axial Dipole (GAD) hypothesis ' , Physics of the Earth and Planetary Interiors , vol. 265 , pp. 54-61 . https://doi.org/10.1016/j.pepi.2017.02.008
\end{abstract}

http://hdl.handle.net/10138/309174

https://doi.org/10.1016/j.pepi.2017.02.008

cc_by_nc_nd

acceptedVersion

Downloaded from Helda, University of Helsinki institutional repository.

This is an electronic reprint of the original article.

This reprint may differ from the original in pagination and typographic detail.

Please cite the original version. 


\section{Accepted Manuscript}

A paleointensity test of the Geocentric Axial Dipole (GAD) hypothesis

Toni Veikkolainen, Moritz Heimpel, Michael E. Evans, Lauri J. Pesonen,

PHYSICS

OF THE EARTH

AND PLANETARY

INTERIORS

\section{Kimmo Korhonen}

PII:

S0031-9201(16)30182-0

DOI:

http://dx.doi.org/10.1016/j.pepi.2017.02.008

Reference:

PEPI 6008

To appear in:

Physics of the Earth and Planetary Interiors

Received Date: $\quad 1$ September 2016

Revised Date: $\quad 13$ February 2017

Accepted Date: $\quad 13$ February 2017

Please cite this article as: Veikkolainen, T., Heimpel, M., Evans, M.E., Pesonen, L.J., Korhonen, K., A paleointensity test of the Geocentric Axial Dipole (GAD) hypothesis, Physics of the Earth and Planetary Interiors (2017), doi: http://dx.doi.org/10.1016/j.pepi.2017.02.008

This is a PDF file of an unedited manuscript that has been accepted for publication. As a service to our customers we are providing this early version of the manuscript. The manuscript will undergo copyediting, typesetting, and review of the resulting proof before it is published in its final form. Please note that during the production process errors may be discovered which could affect the content, and all legal disclaimers that apply to the journal pertain. 


\section{A paleointensity test of the Geocentric Axial Dipole (GAD) hypothesis}

Toni Veikkolainen ${ }^{1 *}$, Moritz Heimpel ${ }^{2}$, Michael E. Evans ${ }^{2}$, Lauri J. Pesonen ${ }^{1}$, and Kimmo Korhonen ${ }^{3}$

(1) Department of Physics, University of Helsinki, P.O. Box 64, 00014 Helsinki, Finland

(2) Department of Physics, University of Alberta, T6G 2E1 Edmonton, Canada

(3) Geological Survey of Finland, P.O. Box 96, 02151 Espoo, Finland

* Corresponding author, email: toni.veikkolainen@helsinki.fi, tel. +358407645113

Keywords: paleomagnetism; geodynamo; time series; intensity; dipole; octupole

\section{Highlights}

- A paleointensity-based test of the Geocentric Axial Dipole hypothesis is presented

- Precambrian and Phanerozoic data are analyzed separately

- Plausible intensity models support the hypothesis of three dominant regimes of geodynamo

- The superposition of a dipole and a small octupole is favored over a dipole alone

\section{Abstract}

The Geocentric Axial Dipole (GAD) model is central to many aspects of geophysics, including plate tectonics and paleoclimate. But its validity is by no means firmly established, particularly for the Precambrian. One test that has met with some success involves the distribution of paleomagnetic inclination angles. It works because any given field morphology has its own distinct probability distribution function (PDF) against which data compilations can be tested. Here, we investigate a second possible test using 
published paleointensity data. Once again, any given field morphology has a specific PDF of intensity. Likely field models consist of an underlying GAD on which is superimposed modest zonal quadrupole and octupole components. The corresponding paleointensity PDFs turn out to have more complicated shapes than their inclination counterparts, often having multiple maxima and minima. Given sufficient data, this complexity offers greater discrimination between models. In this paper, the potential of the paleointensity test is assessed using an extension of the PINT paleointensity database. We found it useful to analyze the Phanerozoic and Precambrian intervals separately. Despite the inherent limitations of this kind of analysis, a tripartite geodynamo with small zonal multipoles appears to be a good starting point on a way towards more fine-tuned models.

\section{Introduction}

The morphology of the geomagnetic field is of considerable interest to several areas of geophysics: plate tectonics, paleoclimate, and the dynamics of the liquid outer core. A long-standing assumption is that of a geocentric axial dipole (GAD). But the validity of this model is still under debate, particularly for the Precambrian. The various prePangaean configurations of continental crust - for example, supercontinents Rodinia (Meert and Torsvik, 2003; Li et al. 2008) and Columbia/Nuna (Rogers and Santosh, 2002; Evans and Mitchell, 2011) - rely heavily on paleomagnetic data, and must therefore remain rather speculative until the GAD model is firmly established. Results based on the inclination test (Evans, 1976) suggest that the field has been close to GAD for the majority of Earth's history (Veikkolainen et al. 2014a,b), yet the inherent non-uniqueness of the method calls for independent verification.

Directional data have generally been favored over intensity data because of the sparseness of the absolute paleointensity record. However, the outcome of several recent studies, and the introduction of objective quality criteria for intensity data (Paterson et al. 2014; Biggin et al. 2015), have improved the situation. In the determination of intensity (F), the double-heating technique of Thellier and Thellier (1959) has remained the most 
widely used method, but this has been supplemented by a number of other methods such as the multispecimen parallel differential partial thermoremanent magnetism method which may provide estimates closer to the actual geomagnetic field intensity, due to its lower sensitivity to the domain state of the magnetized grains (Michalk et al. 2008).

In the past, paleointensities have often been analysed in terms of corresponding virtual dipole moments (VDMs). But this rather begs the question because a GAD model is assumed in order to derive a VDM. It is more sensible to analyse the actual field intensity values reported from each sampling site. We begin by deriving the probability distribution functions (PDFs) of a range of models likely to be of interest: GAD, GAD \pm small (5-10\%) zonal quadrupole or octupole components. We then seek insights from geodynamo simulations representing various relevant scenarios. Finally, we analyse a global compilation of paleointensity data to assess to what extent the GAD is supported, and to draw inferences about its long-term behaviour.

\section{Theoretical models}

Latitudinal intensity profiles of geocentric axial dipole, quadrupole, and octupole fields are illustrated in Fig. 1. These serve as a useful reference, but experience shows that compound models consisting of a main dipole (GAD) with modest higher-order (quadrupole, octupole) components are likely to be more appropriate. For a geocentric axial dipole, the inclination and intensity at the Earth's surface are given by:

$\mathrm{I}=\arctan (2 \tan \lambda)$

$\mathrm{F}=\mathrm{F}_{0}\left(1+3 \sin ^{2} \lambda\right)^{1 / 2}$

where $\lambda$ is latitude and $F_{0}$ is intensity at the equator, defined by Equation 3:

$$
\mathrm{F}_{0}=\mu_{0} \mathrm{~m} /\left(4 \pi \mathrm{r}^{3}\right)
$$


where $\mu_{0}$ is vacuum permeability, $m$ is dipole moment and $r$ is the Earth's radius. The lengths of latitude lines (small circles), and number of samples in a data scale like $\sin \lambda$. Thus the corresponding probability density functions (PDFs) for inclination and intensity for a GAD field are given by::

$$
\begin{aligned}
& \mathrm{P}_{\mathrm{GAD}}^{\mathrm{I}}=\sin \{\arctan [(\tan \mid \mathrm{II}) / 2]\} \\
& \mathrm{P}_{\mathrm{GAD}}^{\mathrm{F}}=\left[\left(\mathrm{F}^{2}-1\right) / 3\right]^{1 / 2}
\end{aligned}
$$

These PDFs and their associated cumulative distribution functions (CDFs) are illustrated in Fig. 2, which also includes the case of a GAD plus a $20 \%$ zonal octupole.

So far, we have considered only simple, static global fields. Over time, however, the field may undergo reversals and changes in multipolar content. Thus, it is also interesting to evaluate probability distributions for superpositions of simple fields, with each different field representing a different time period. We restrict ourselves to intensity distributions, which are the focus of this paper. As an example, consider a magnetic field time history of a GAD superposed with $10 \%$ positive and negative $10 \%$ octupole contributions in equal time contributions. The outcome is shown in Fig. 3. Even this simple case is relatively complex, having three distinct maxima (Fig. 3e). This complexity may offer more discrimination between models than their inclination counterparts.

\section{Geodynamo simulations}

We use numerical dynamo simulations to test the idea that intensity distributions based on the first three zonal Gauss coefficients can adequately characterize the geomagnetic field. Two scenarios are investigated, corresponding to Cases $1 \mathrm{~b}$ and $3 \mathrm{~b}$ of Heimpel and Evans (2013). Case 1b models present-day Earthlike conditions with buoyancy flux concentrated at the inner core boundary. Case $3 \mathrm{~b}$ models an ancient geodynamo with buoyancy flux only at the core-mantle boundary. The Rayleigh numbers in these cases are $2.1 \times 10^{7}$ and $8.3 \times 10^{6}$, and the time-averaged Reynolds numbers are 664 and 598, respectively. Heimpel and Evans (2013) found that Case 1b produces a field that closely 
resembles an ideal GAD field, whereas Case $3 \mathrm{~b}$ results in a time-averaged field that has a significant zonal octupole component of about $11 \%$ of the GAD strength. Fig. 4 presents intensity time series, cumulative distribution functions (CDFs) and probability density functions (PDFs). For the dynamo models we obtain a set of Gauss coefficients at each model time step and plot the dipole, quadrupole and octupole coefficients (Fig 4a and 4d) as time series. The maximum spherical harmonic degree is $l_{\max }=48$ for Cases $1 \mathrm{~b}$ and $3 \mathrm{~b}$, (Heimpel and Evans, 2013). We use the full resolution model intensity fields to generate the full model intensity distributions, and the dipole, quadrupole and octupole coefficients to generate the simplified intensity distributions (Fig 4). Distributions are shown for a single time step (snapshot) in Fig 4b and Fig 4e. In addition distributions are shown for the time averaged intensity fields (Fig 4c and Fig 4f), and for simplified distributions that are obtained by averaging $\lg _{1}{ }^{0} \mathrm{l}, \mathrm{G} 2=\mathrm{g}_{2}{ }^{0} / \mathrm{g}_{1}{ }^{0}$, and $\mathrm{G} 3=\mathrm{g}_{3}{ }^{0} / \mathrm{g}_{1}{ }^{0}$ (Fig $4 \mathrm{c}$ and Fig $4 \mathrm{f}$ ).

The intensity statistics were compiled by sampling the magnetic field outside the source region at a radius corresponding to the surface of the Earth, i.e. at $r=1.83 r_{o}$, where $r_{o}$ is the radius of the outer boundary of the dynamo model, which is the core-mantle boundary. Sampling of the magnetic field components was performed at $\mathrm{N}=901$ points, distributed randomly over the sphere in an equal-area sense. This number of sampling points is chosen to be intermediate between the number of paleointensity data for the Precambrian $(\mathrm{N}=313)$ and Phanerozoic $(\mathrm{N}=1964)$. This choice of $\mathrm{N}$ for dynamo sampling allows for comparison between intensity distributions derived from the models and those derived from paleointensity data. The dynamo model results show that the first three zonal Gauss coefficients broadly characterize these magnetic fields for snapshots in time, and also for time series. The time averaging is over about one diffusion time scale, $\tau$ $=D^{2} / \eta$, where $D$ is the thickness of the outer core $(2260 \mathrm{~km})$ and $\eta$ is the magnetic diffusivity of liquid iron $\left(2 \mathrm{~m}^{2} \mathrm{~s}^{-1}\right)$. For our simulations, $\tau$ is 81 thousand years. For Case 1b, the snapshot (Fig. 4b) shows that the ideal GAD field represents the intensity statistics fairly well, except at the lowest intensities, below $80 \mu \mathrm{T}$. Although the quadrupole and octupole contributions are small, including them does improve the fit. For Case $3 b$, however, the ideal GAD does not fit well because of the strong octupole component (Fig. 4e). A much better fit is obtained if the computed quadrupole and 
octupole components are included. Comparing the snapshots to the time-averaged statistics (Fig. 4c,f), we see that time averaging stretches out the range of intensities. This degrades the fits, but inclusion of the quadrupole and octupole terms still improves the situation. We note that, unlike our idealized theoretical models, which are based on a single component (zonal dipole) or triplet (zonal dipole, quadrupole, octupole), the dynamo model fields include contributions from all spherical harmonics up to the resolution of the model (maximum spherical harmonic degree, $l_{\max }=48$, very high for the cases considered here). Thus the wider range of intensities is expected for the distributions obtained from the full dynamo model magnetic fields.

The dynamo simulations indicate that models including higher-order terms, particularly $\mathrm{g}_{3}{ }^{0}$, are likely to offer more realistic solutions than pure GAD fields. But we note that such simple models fail to encompass the whole range of intensities produced by the simulations, especially the nonzero low field intensities in $4 b-f$. We return to this problem further below, after discussing the CALS10k observational magnetic field model, and describing the available experimental paleointensity data to which the various models will ultimately be compared.

\section{The CALS10k observational magnetic field model}

We obtain intensity CDFs and PDFs for the CALS10k observational model, which gives the Earth's magnetic field from 10 ka to the year 1990 with a resolution defined by the maximum spherical harmonic degree $_{\max }=10$ (Korte et al. 2011). Heimpel and Evans (2013) carried out a similar analysis for inclination distributions. As with the dynamo models described above, the magnetic field components are sampled at 901 points on the sphere. The resulting CDFs and PDFs from the CALS10k field model, and the idealized distributions based on the first three zonal Gauss coefficients $\left(\mathrm{g}_{1}{ }^{0}, \mathrm{~g}_{2}{ }^{0}\right.$, and $\mathrm{g}_{3}{ }^{0}$, where subscript means order and superscript means degree), are shown in Fig. 5. Also shown are time series of $\mathrm{g}_{1}{ }^{0}, \mathrm{~g}_{2}{ }^{0}$, and $\mathrm{g}_{3}{ }^{0}$. These indicate that the geomagnetic field has been dominantly dipolar over the past $10 \mathrm{kyrs}$, with roughly $7 \%$ quadrupole contribution and a smaller octupole contribution. We compare statistics for a snapshot in time (for the year 
1990) and for a time average (over 10000 years). The time-averaged CDF and PDF are reasonably well approximated by a simple dipole distribution. The main difference between the snapshot and the time-averaged field is that time averaging extends the range of intensities, and therefore a single zonal model may be in certain situations more suitable for a snapshot of a field.

\section{The data}

Our paleointensity compilation derives mainly from the online PINT database (http://earth.liv.ac.uk/pint/), supplemented by recently-published results. Because the Precambrian part of PINT was recently updated for the analysis by Biggin et al. (2015), most of our additions are Phanerozoic. They include data from various locations, such as the Pacific Ocean (Yamazaki and Yamamoto, 2014), South Korea (Chang et al. 2013), Namibia (Sprain et al. 2016), Iceland (Cromwell et al. 2015; Tanaka and Yamamoto, 2016), the Canary Islands (Caccavari et al. 2015) and Ethiopia (Ahn et al. 2016).

To focus on long-term trends, and to remove the bias caused by the overwhelming amount of geologically young data, we exclude observations with ages less than 1 million years. We divide the remaining data into two subsets: Phanerozoic (1-540 Ma) and Precambrian (>540 Ma). In an attempt to identify the better results and to provide objective grounds for rejecting poorer data, Biggin and Paterson (2014) proposed a scheme for assessing paleointensity information, paralleling the seminal work of Van der Voo (1990) for judging paleomagnetic directions. Their scheme comprised eight quality criteria, to which Biggin et al. (2015) added a ninth, dealing with the public availability of data. The overall assessment of a given paleointensity result is expressed in terms of a quality index $\mathrm{Q}_{\mathrm{PI}}$ which ranges from 0 to 9.

For pre-540 Ma data unavailable in PINT, we determined QPI ourselves. After eliminating results with $\mathrm{Q}_{\mathrm{PI}}=0$, there are 313 Precambrian paleointensity results from 35 studies (Appendix 1); their mean is $26 \mu \mathrm{T}$. Their temporal distribution is by no means 
ideal (Fig. 6), with concentrations (representing more than half the data) at 1080-1090 Ma, 1300-1310 Ma, 1840-1850 Ma, 2440-2450 Ma, and 2740-2750 Ma, obtained from the Central Arizona diabases (Donadini et al. 2011), the Lake Shore Traps (Kulakov et al. 2013), the Gardar lavas (Thomas and Piper, 1995), the Sudbury irruptive (Schwarz and Symons, 1970), the Matachewan dykes (Macouin et al. 2003; Smirnov and Tarduno, 2005; Halls et al. 2004), the Burakovka intrusion (Smirnov et al. 2003) and the Stillwater Complex (Selkin et al. 2008).

The daunting task of assigning QPI values to the entire 1-540 Ma dataset (2987 observations from 197 studies) has not yet been attempted, but we have tried to eliminate the least reliable data by ensuring that a sufficient number of samples has been investigated, or that a state-of-the-art method for the intensity determination with pTRM checks has been used. Therefore, we ended up using our truncated $\mathrm{Q}_{\text {PI }}$ estimate $T r \mathrm{Q}_{\mathrm{PI}}$. In practice, this meant that the 'STAT' and/or the 'ALT' criteria were met, i.e. TrQPI was 2 or 1. Rejection of data with $\mathrm{TrQ}_{\mathrm{PI}}=0$ reduces the number of observations to 1964 from 154 studies (Appendix 2). In this case, the mean is $27 \mu \mathrm{T}$. Fig. 7 shows that, once again, the temporal distribution is not ideal. Despite the exclusion of post-1 Ma observations, the youngest bin still contains one third of the data, whereas there are very few data prior to $400 \mathrm{Ma}$.

\section{Results}

Due to their significantly different data densities, the Precambrian and Phanerozoic were analyzed separately. The frequency distribution of the Precambrian data, binned in $4 \mu \mathrm{T}$ intervals, is shown in Fig. 8. To facilitate comparison, the same bin size was used for the Phanerozoic data. The choice of a bin size is always a trade-off between an adequate number of observations in each bin and the ability of different models to produce sufficiently different histograms with characteristic maxima and minima.

In our Precambrian data, the presence of several distinct peaks rules out a model consisting of a single GAD. This is no surprise - it is highly unlikely that a single, fixed 
dipole existed throughout the Precambrian. Thus, we start by considering models with 2 and 3 GADs, choosing their strengths by by inspection, but ensuring that the mean field strength lies within $5 \%$ of that of the observations. Each model was a superposition of frequency histograms of distinct fields which were present at non-overlapping time instances. Models consisted of 100000 synthetic data points, and the noise in the synthetic data was assumed Gaussian. No actual order for time instances was assumed.

For the 2-GAD model we chose $\mathrm{g}_{1}{ }^{0}$ values of $7 \mu \mathrm{T}$ and $20 \mu \mathrm{T}$, giving equal weight to each (i.e. each GAD exists for a total of half the time, regardless of the actual temporal history). The corresponding field-intensity distribution crudely mimics that of the Precambrian observations, but the Kolmogorov-Smirnov (K-S) test yields $\mathrm{P}=3 \times 10^{-4}$, well below the commonly used threshold of $\mathrm{P}=0.05$. The null hypothesis - that the two distributions are identical—must be rejected. We next tried a 3-GAD model with $\mathrm{g}_{1}{ }^{0}$ values of $7 \mu \mathrm{T}, 18 \mu \mathrm{T}$, and $32 \mu \mathrm{T}$, with durations of $1 / 4: 1 / 2: 1 / 4$. This model passes the K-S test with $\mathrm{P}=0.17$ (Appendix 3). Of course, our procedure is non-unique, but it is interesting to discover that such a simple model can reasonably reproduce the observations. The fit is much improved by adding small octupole components, in line with results of inclination-based analyses of Precambrian data (Veikkolainen et al. 2014a,b). Octupole components of both signs are included, as described for the model summarized in Fig. 3. The $5 \%$ and $10 \%$ octupoles (i.e. $\mathrm{g}_{3}{ }^{0}= \pm 0.35 \mu \mathrm{T}, \pm 0.9 \mu \mathrm{T}, \pm 1.6 \mu \mathrm{T}$, and $\mathrm{g}_{3}{ }^{0}= \pm 0.7 \mu \mathrm{T}, \pm 1.8 \mu \mathrm{T}, \pm 3.2 \mu \mathrm{T}$ ) yield $\mathrm{P}=0.49$ and $\mathrm{P}=0.72$, respectively (Appendix 3 ). The field intensity distributions for the GAD with $10 \%$ octupole model and that of GAD with $10 \%$ quadrupole model are compared to the Precambrian data in Fig. 8. They all have the same mean value, namely $26 \mu \mathrm{T}$. We found that replacing the $5 \%$ and $10 \%$ octupoles by quadrupoles of same magnitude (i.e. $\mathrm{g}_{2}{ }^{0}= \pm 0.35 \mu \mathrm{T}, \pm 0.9 \mu \mathrm{T}, \pm 1.6 \mu \mathrm{T}$, and $\left.\mathrm{g}_{2}{ }^{0}= \pm 0.7 \mu \mathrm{T}, \pm 1.8 \mu \mathrm{T}, \pm 3.2 \mu \mathrm{T}\right)$ results in poorer, yet statistically acceptable $\mathrm{P}$ values $(0.30$ and 0.49; Appendix 3).

The Phanerozoic data are summarized in Fig. 9. The distribution appears different from that of Precambrian observations. The two main peaks seen in the latter have broadened and almost eliminated the intervening minimum. However, we note that like its Precambrian counterpart, the Phanerozoic histogram has a prominent shoulder centered 
near $\sim 40 \mu \mathrm{T}$. Given these properties, we first tried comparing the Phanerozoic data to the models used for the Precambrian: the K-S test yielded $\mathrm{P}=0.03$ and $\mathrm{P}=0.12$ for the $3-\mathrm{GAD}$ with $5 \%$ and $10 \%$ octupoles, respectively (Appendix 3). They both have the same mean value as the data, namely $27 \mu \mathrm{T}$. The replacement of $5 \%$ or $10 \%$ octupole content by a quadrupole content of similar strength resulted in situations where $\mathrm{P}=0.03$ or $\mathrm{P}=0.06$ (Appendix 3). Once again, 10\% octupole content is favored, although neither model fits the Phanerozoic data as well as the Precambrian. In particular, the 2-GAD and 3-GAD models with no additional quadrupole or octupole field are unhelpful in explaining the observed distribution.

\section{Discussion and conclusions}

The possibility that global compilations of paleointensity results might provide a test of the geocentric axial dipole (GAD) model has been investigated. Numerical dynamo simulations indicate that the time-averaged geomagnetic field is likely to be dominated by the axial dipole $\left(\mathrm{GAD}\right.$, or $\left.\mathrm{g}_{1}{ }^{0}\right)$ component, but will generally contain higher-order zonal components. In particular, the zonal octupole $\left(\mathrm{g}_{3}{ }^{0}\right)$ component may exceed $10 \%$ of $\mathrm{g}_{1}{ }^{0}$. Given these expectations, the intensity distributions of relevant theoretical models are derived. These are compared to an expanded global paleointensity database by analyzing the Precambrian and Phanerozoic separately. The paleointensity distributions for both intervals can be very roughly explained by the same geomagnetic model. It consists of three parts, each being a GAD with a $10 \%$ octupole field. Specifically, the $\mathrm{g}_{1}{ }^{0}$ values are $7 \mu \mathrm{T}, 18 \mu \mathrm{T}$, and $32 \mu \mathrm{T}$. The $18 \mu \mathrm{T}$ field lasts for $50 \%$ of the time, whereas the others each last $25 \%$ of the time. The actual temporal history does not matter, as long as the total accumulated time for each field is achieved. The model is non-unique but it is interesting (even surprising) to discover that such a simple model can be used as a first-order approximation, although we also admit that adding further complexity is likely to provide better fits to the observations in the Phanerozoic..

An early proposal by Cox (1968), based on the double-disc dynamo of Rikitake (1958), suggested that the Earth's dipole moment varies sinusoidally about a nonzero mean until a 
polarity reversal occurs. Thereafter, it behaves in the same way about a nonzero mean of the opposite sign. The model had some appeal, but Kono (1972) and McFadden and McElhinny (1982) convincingly demonstrated that it fails to predict an intensity distribution anything like the observations. Models composed of a series of constant field strengths, as we suggest, do a better job of explaining the data. Instead of an oscillatory behaviour, a step-like history is envisaged. Any number of field plateaus can be hypothesized, but it seems that three suffice - especially if small stochastic fluctuations are allowed. This tripartite solution is consistent with the suggestion that the geodynamo is driven by three dominant regimes (Gallet and Pavlov, 2016; Heimpel and Evans, 2013; Olson and Amit, 2015). These authors, and others, enquire how the Earth's thermal evolution affects the known variations in reversal frequency, but do not explicitly consider the strength of the geomagnetic field. But this has recently been done by Driscoll (2016) who obtains a geomagnetic history that, for the most part, consists of three dipole moment values centred on $\sim 15 \mathrm{ZAm}^{2}, \sim 55 \mathrm{ZAm}^{2}$, and $\sim 80 \mathrm{ZAm}^{2}$. These are remarkably similar to those we obtain from our paleointensity analysis: $\mathrm{g}_{1}{ }^{0}$ values of 7 $\mu \mathrm{T}, 18 \mu \mathrm{T}$, and $32 \mu \mathrm{T}$ correspond to dipole moments of $18 \mathrm{ZAm}^{2}, 47 \mathrm{ZAm}^{2}$, and 83 $\mathrm{ZAm}^{2}$, respectively. However, the temporal evolution derived by Driscoll (2016) would not satisfy our interpretation of the paleointensity data which requires that the $7 \mu \mathrm{T}, 18$ $\mu \mathrm{T}$, and $32 \mu \mathrm{T}$ plateaus last for $25 \%, 50 \%$, and $25 \%$ of the total time, respectively - for both the Precambrian and the Phanerozoic. Nevertheless, it appears that three-regime models are a good starting point in the search for a comprehensive theory of geomagnetism.

\section{Acknowledgements}

Andrew J. Biggin (University of Liverpool) is credited for the maintenance of the PINT database which was essential to this study. No specific grant from funding agencies was received. Insightful comments of three anonymous reviewers helped us to improve the manuscript.

\section{Supplementary material}


The Precambrian and Phanerozoic paleointensity data used in the study (Appendixes 1 and 2) have been gathered in MS Excel files (Appendix1.xlsx and Appendix2.xlsx), respectively. Kolmogorov-Smirnov test results (Appendix 3) are included in the MS Excel file Appendix3.xlsx. The tables are available in a zip package "appendixes.zip".

\section{References}

Ahn, H.-S., Kidane, T., Yamamoto, Y., Otofuji, Y.-i., 2016. Low geomagnetic field intensity in the Matuyama Chron: palaeomagnetic study of a lava sequence from Afar depression, East Africa. Geophysical Journal International 204, 127-146.

Biggin, A.J., Paterson, G.A., 2014. A new set of qualitative reliability criteria to aid inferences on palaeomagnetic dipole moment variations through geological time. Frontiers in Earth Science, 2, doi:10.3389/feart.2014.00024.

Biggin, A.J., Piispa, E.J., Pesonen, L.J., Holme, R., Paterson, G.A., Veikkolainen, T., Tauxe, L., 2015. Palaeomagnetic field intensity variations suggest Mesoproterozoic inner core nucleation. Nature, 526, 245-248.

Caccavari, A., Calvo-Rathert, M., Goguitchaichvili, A., Soler, V., Huaiyu, H., Vegas, N., 2015. An integrated palaeomagnetic, palaeointensity and ${ }^{40} \mathrm{Ar} /{ }^{39} \mathrm{Ar}$ investigation on a Miocene polarity transition recorded in a lava sequence in la Gomera, Canary Islands. Geophys. J. Int. 200, 1297-1316.

Chang, B., Kim, W., Doh, S.-J., Yu, Y., 2013. Paleointensity determination of Late Cretaceous basalts in northwest South Korea: implications for low and stable paleofield strength in the Late Cretaceous. Earth Planets Space 65, 1501-1513.

Cox, A., 1968. Lengths of Geomagnetic Polarity Intervals. Journal of Geophysical Research 73, 3247-3260. 
Cromwell, G., Tauxe, L., Halldórsson, S.A., 2015. New paleointensity results from rapidly cooled Icelandic lavas: Implications for Arctic geomagnetic strength. J. Geophys. Res. Solid Earth 120, 2913-2934.

Donadini, F., Pesonen, L.J., Korhonen, K., Deutsch, A., Harlan, S.S., 2011. Paleomagnetism and Paleointensity of the 1.1 Ga Old Diabase Sheets from Central Arizona. Geophysica 47, 3-30.

Driscoll, P.E., 2016. Simulating 2 Ga of geodynamo history. Geophysical Research Letters $43,5680-5687$.

Evans, M.E., 1976. Test of the dipolar nature of the geomagnetic field throughout Phanerozoic time. Nature 262, 676-677.

Evans, D.A.D., Mitchell, R.N., 2011. Assembly and breakup of the core of Paleoproterozoic-Mesoproterozoic supercontinent Nuna. Geology 39, 443-446.

Gallet, Y., Pavlov, V.E., 2016. Three distinct reversing modes in the geodynamo. Izvestiya, Physics of the Solid Earth 52, 291-296.

Halls, H.C., McArdle, N.J., Gratton, M.N., Hill, M.J., Shaw, J., 2004. Microwave paleointensities from dyke chilled margins: a way to obtain long-term variations in geodynamo intensity for the last three billion years. Physics of the Earth and Planetary Interiors $147,183-195$.

Heimpel, M.H., Evans, M.E., 2013. Testing the geomagnetic dipole and reversing dynamo models over Earth's cooling history. Physics of the Earth and Planetary Interiors $224,124-131$. 
Kono, M., 1972. Mathematical models of the Earth's magnetic field. Physics of the Earth and Planetary Interiors 5, 140-150.

Korte, M., Constable, C., Donadini, F., Holme, R., 2011. Reconstructing the Holocene Geomagnetic Field. Earth and Planetary Science Letters 312, 497-505.

Kulakov, E.V., Smirnov, A.V., Diehl, J.F., 2013. Absolute geomagnetic paleointensity as recorded by $\sim 1.09$ Ga Lake Shore Traps (Keweenaw Peninsula, Michigan). Studia Geophysica et Geodaetica 57, 565-584.

Li, Z.X., Bogdanova, S.V., Collins, A.S., Davidson, A., De Waele, B., Ernst, R.E., Fitzsimons, I.C.W., Fuck, R.A., Gladkochub, D.P., Jacobs, J., Karlstrom, K.E., Lu, S., Natapov, L.M., Pease, V., Pisarevsky, S.A., Thrane, K., Vernikovsky, V., 2008. Assembly, configuration, and break-up history of Rodinia: A synthesis. Precambrian Research 160, 179-210.

Macouin, M., Valet, J.P., Besse, J., Buchan, K., Ernst, R., LeGoff, M., Scharer, U., 2003. Low paleointensities recorded in 1 to 2,4 Ga Proterozoic dykes, Superior Province, Canada. Earth and Planetary Science Letters 213, 79-95.

McFadden, P.L., McElhinny, M.W., 1982. Variations in the geomagnetic dipole, 2. Statistical analysis of VDMs for the past 5 million years. Journal of Geomagnetism and Geoelectricity 34, 163-189.

Meert, J.G., Torsvik, 2003. The making and unmaking of a supercontinent: Rodinia revisited. Tectonophysics 375, 261-288.

Michalk, D.M., Muxworthy, A.R., Böhnel, H.N., Maclennan, J., Nowaczyk, N., 2008. Evaluation of the multispecimen parallel differential pTRM method: a test on historical lavas from Iceland and Mexico. Geophysical Journal International 173, 409-420. 
Olson, P., Amit, H., 2015. Mantle superplumes induce geomagnetic superchrons. Frontiers in Earth Science 15, doi: 10.3389/feart.2015.00038.

Paterson, G.A., Tauxe, L., Biggin, A.J., Shaar, R., Jonestrask, L.C., 2014. On improving the selection of Thellier-type paleointensity data. Geochemistry Geophysics Geosystems $15,1180-1192$.

Rikitake, T., 1958. Oscillations of a system of disk dynamos. Proceedings of the Cambridge Philosophical Society 54, 89-105.

Rogers, J.J.W., Santosh, M., 2002. Configuration of Columbia, a Mesoproterozoic supercontinent. Gondwana Research 5, 5-22.

Schwarz, E.J., Symons, D.T.A., 1970. Paleomagnetic field intensity during cooling of the Sudbury irruptive 1700 million years ago. Journal of Geophysical Research 75, 66316640.

Selkin, P.A., Gee, J.S., Meurer, W.P., Hemming, S.R., 2008. Paleointensity record from the 2.7 Ga Stillwater Complex, Montana. Geochemistry Geophysics Geosystems 9, doi: 10.1029/2008GC001950.

Smirnov, A.V., Tarduno, J.A., 2005. Thermochemical remanent magnetization in Precambrian rocks: Are we sure the geomagnetic field was weak? Journal of Geophysical Research 110, doi: 10.1029/2004JB003445.

Smirnov, A.V., Tarduno, J.A., Pisakin, B.N., 2003. Paleointensity of the early geodynamo $(2,45 \mathrm{Ga})$ as recorded in Karelia: a single-crystal approach. Geology 31, 415418.

Sprain, C.J., Feinberg, J.M., Geissman, J.W., Strauss, B., Brown, M.C., 2016.

Paleointensity during periods of rapid reversal: A case study from the Middle Jurassic 
Shamrock batholith, western Nevada. Geological Society of America Bulletin 128, 223238.

Tanaka, H., Yamamoto, Y., 2016. Palaeointensities from Pliocene lava sequences in Iceland: emphasis on the problem of Arai plot with two linear segments. Geophys. J. Int. 205, 694-714.

Thellier, E., Thellier, O., 1959. Sur l'intensité du champ magnétique terrestre dans le passé historique et géologique. Annales de géophysique 15, 285-378.

Thomas, D.N., Piper, J.D.A., 1995. Evidence for the existence of a transitional geomagnetic field recorded in a Proterozoic lava succession. Geophysical Journal International 122, 266-282.

Van der Voo, R., 1990. The reliability of paleomagnetic data. Tectonophysics 184, 1-9.

Veikkolainen, T., Pesonen, L.J., Korhonen, K., Evans, D.A.D., 2014a. On the lowinclination bias of the Precambrian geomagnetic field. Precambrian Research 244, 23-32.

Veikkolainen, T., Pesonen, L.J., Korhonen, K., 2014b. An analysis of geomagnetic field reversals supports the validity of the Geocentric Axial Dipole (GAD) hypothesis in the Precambrian. Precambrian Research 244, 33-41.

Yamazaki, T., Yamamoto, Y., 2014. Paleointensity of the geomagnetic field in the Late Cretaceous and earliest Paleogene obtained from drill cores of the Louisville seamount trail. Geochemistry Geophysics Geosystems 15, 2454-2466.

Figure captions 
Fig. 1: Field intensity as a function of colatitude for a geocentric axial dipole (GAD), quadrupole (GAQ), and octupole (GAO) normalized to the equatorial dipole value. One column figure

Fig. 2: Probability density functions (PDF) and cumulative distribution functions (CDF) for inclination (a) and intensity (b) for a geocentric axial dipole (GAD) field and for a GAD plus $20 \%$ octupole field.

Two column figure

Fig. 3: Intensity vs. colatitude (a), and corresponding intensity distributions (b,c) and their superpositions (d,e) for a GAD (black dashed lines), GAD $+10 \%$ octupole (red lines) and GAD - 10\% octupole (blue lines). Combined distributions are superpositions of GAD $+10 \%$ octupole and GAD - $10 \%$ octupole, each lasting $50 \%$ of the total time. For interpretation of the references to color, the reader is referred to the online version of this article.

Two column figure

Fig. 4: Time series and intensity distributions for the present-era dynamo model (case 1) (a,b,c) and for the ancient dynamo model (case 3) (d,e,f). Time series (a,d) show the first three zonal Gauss coefficients, $\mathrm{g}_{1}{ }^{0}, \mathrm{~g}_{2}{ }^{0}$, and $\mathrm{g}_{3}{ }^{0}$. For clarity, $\mathrm{g}_{2}{ }^{0}$ and $\mathrm{g}_{3}{ }^{0}$ are magnified by a factor of 10 . The abscissa is labelled in terms of the magnetic diffusion timescale, $\tau$ ( $\sim 80 \mathrm{kyrs})$. CDFs and PDFs for the dynamo simulations are shown by blue and green lines with circle markers. CDFs (PDFs) for a GAD with $\mathrm{g}_{1}{ }^{0}$ equal to that of the dynamo models for snapshots $(b, e)$ and for time averages (c,f) are shown as solid (dashed) black lines. Corresponding CDFs (PDFs) for fields composed of $\mathrm{g}_{1}{ }^{0}, \mathrm{~g}_{2}{ }^{0}$, and $\mathrm{g}_{3}{ }^{0}$ components equal to those of the dynamo models are shown by red solid (dashed) lines. For interpretation of the references to color, the reader is referred to the online version of this article.

Two column figure

Fig. 5. Time series and intensity distributions for the CALS10k magnetic field model of Korte et al. (2011). Time series (a) show the first three zonal Gauss coefficients, $\mathrm{g}_{1}{ }^{0}, \mathrm{~g}_{2}{ }^{0}$, 
and $\mathrm{g}_{3}{ }^{0}$. For clarity, $\mathrm{g}_{2}{ }^{0}$ and $\mathrm{g}_{3}{ }^{0}$ are magnified by a factor of 10 . The abscissa is labelled in years from $10 \mathrm{ka}$ to 1990 . CDFs and PDFs for the dynamo simulations are shown by blue and green lines with circle markers. CDFs (PDFs) for a GAD with $\mathrm{g}_{1}{ }^{0}$ equal to that of the field model for the year 1990 (b), and for the time average over $10 \mathrm{ka}$ are shown as solid (dashed) black lines. Corresponding CDFs (PDFs) for fields composed of $\mathrm{g}_{1}{ }^{0}, \mathrm{~g}_{2}{ }^{0}$, and $\mathrm{g}_{3}{ }^{0}$ components equal to those of the field model are shown by red solid (dashed) lines. For interpretation of the references to color, the reader is referred to the online version of this article.

One column figure

Fig. 6. Histogram of Precambrian paleointensity data $(\mathrm{N}=313)$ as a function of age (10 Ma bins).

One column figure

Fig. 7. Histogram of Phanerozoic paleointensity data $(\mathrm{N}=1964)$ as a function of age (10 Ma bins).

One column figure

Fig. 8. Frequency histogram ( $4 \mu \mathrm{T}$ bins) of Precambrian paleointensity observations $(\mathrm{N}=313)$ and geomagnetic field models (100000 synthetic points). The model parameters are $\mathrm{g}_{1}{ }^{0}=7 \mu \mathrm{T}, 18 \mu \mathrm{T}, 32 \mu \mathrm{T}, \mathrm{g}_{2}{ }^{0}= \pm 0.7 \mu \mathrm{T}, \pm 1.8 \mu \mathrm{T}, \pm 3.2 \mu \mathrm{T}$ and $\mathrm{g}_{3}{ }^{0}= \pm 0.7 \mu \mathrm{T}, \pm 1.8 \mu \mathrm{T}$, $\pm 3.2 \mu \mathrm{T}$. The temporal fractions covered by these three ingredients are $1 / 4: 1 / 2: 1 / 4$. One column figure

Fig. 9. Frequency histogram ( $4 \mu \mathrm{T}$ bins) of Phanerozoic paleointensity data $(\mathrm{N}=1964)$ and geomagnetic field models (100000 synthetic points). The model parameters are $\mathrm{g}_{1}{ }^{0}=7 \mu \mathrm{T}$, $18 \mu \mathrm{T}, 32 \mu \mathrm{T}, \mathrm{g}_{2}{ }^{0}= \pm 0.7 \mu \mathrm{T}, \pm 1.8 \mu \mathrm{T}, \pm 3.2 \mu \mathrm{T}$ and $\mathrm{g}_{3}{ }^{0}= \pm 0.7 \mu \mathrm{T}, \pm 1.8 \mu \mathrm{T}, \pm 3.2 \mu \mathrm{T}$. The temporal fractions covered by these three ingredients are 1/4:1/2:1/4. One column figure

\section{Figures}




\section{ACCEPTED MANUSCRIPT}

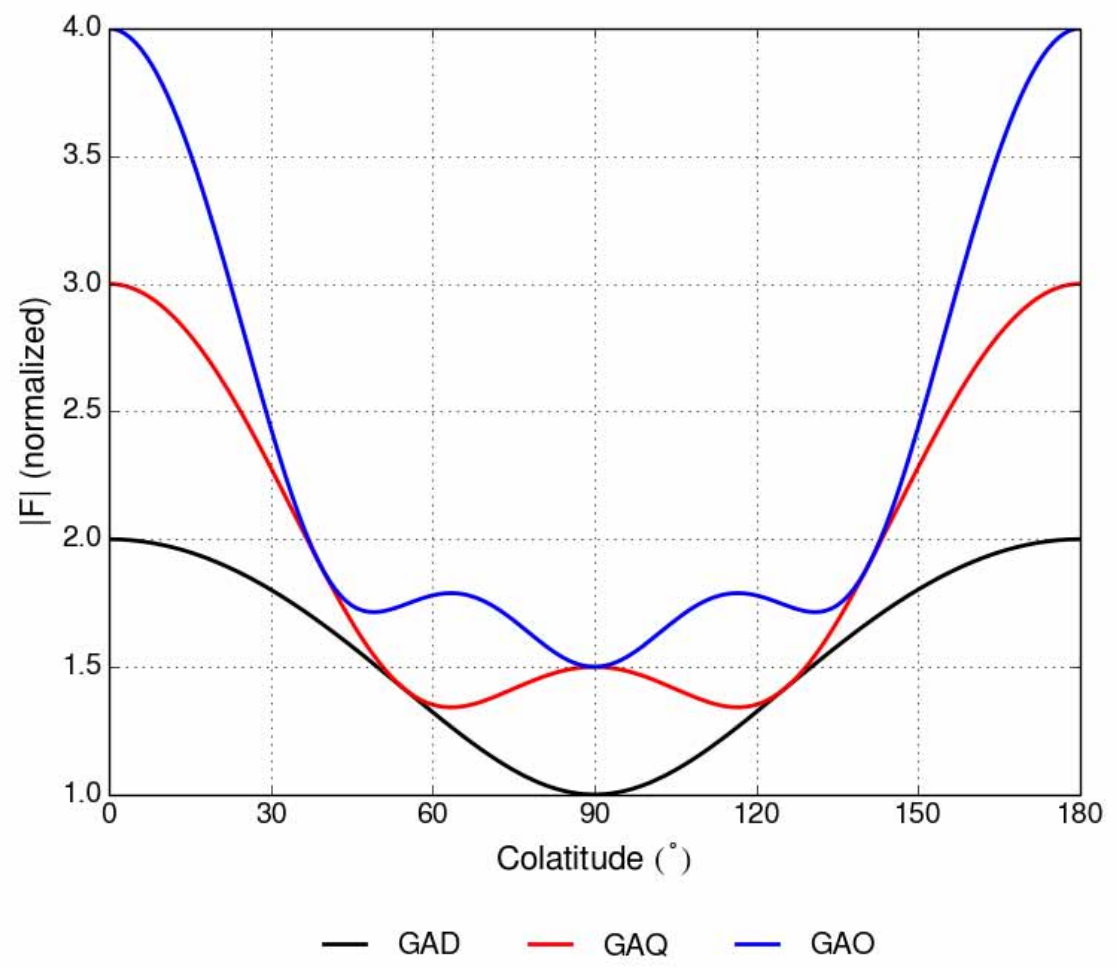

Fig. 1. 

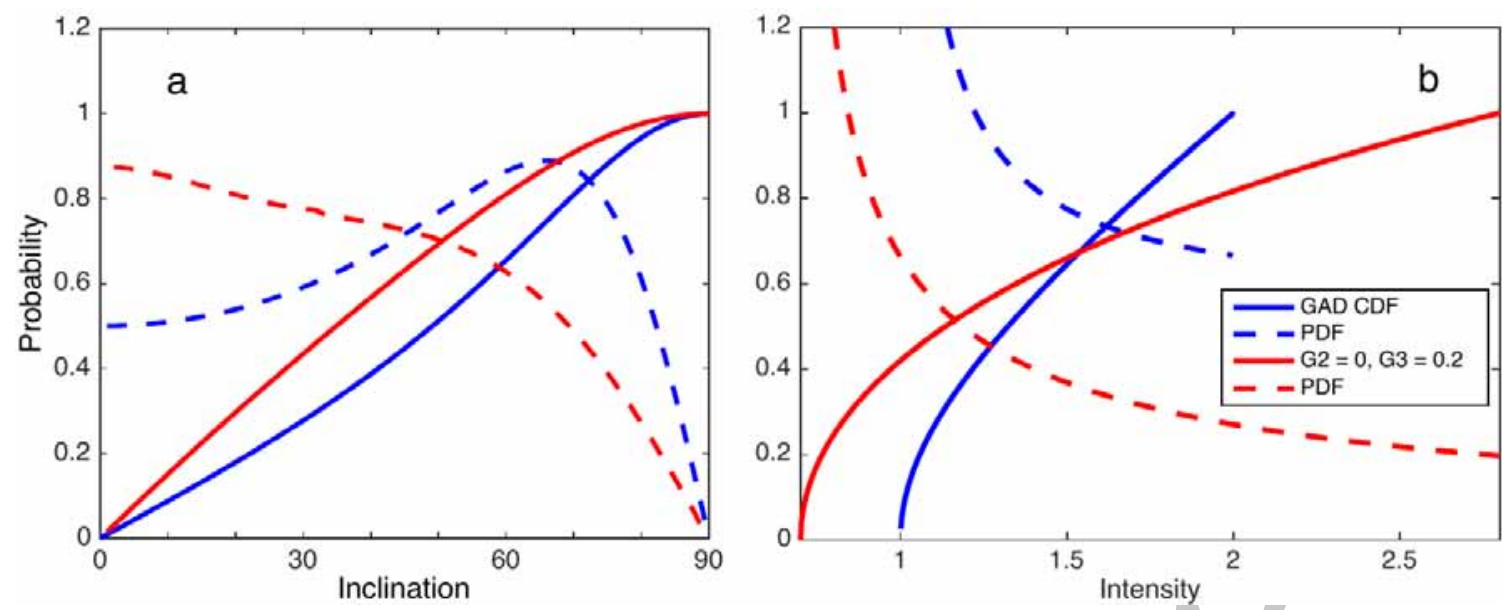

Fig. 2. 

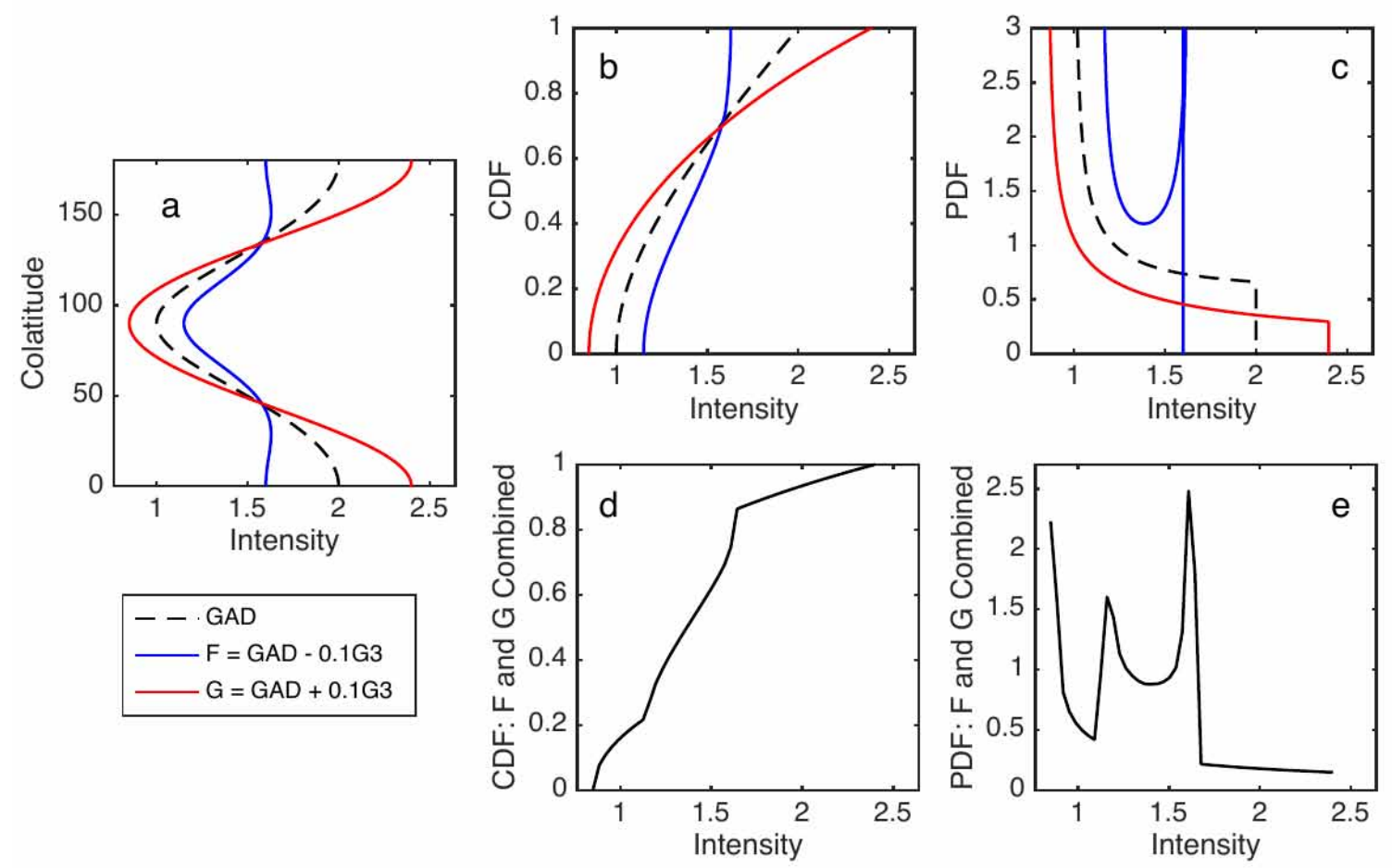

Fig. 3. 

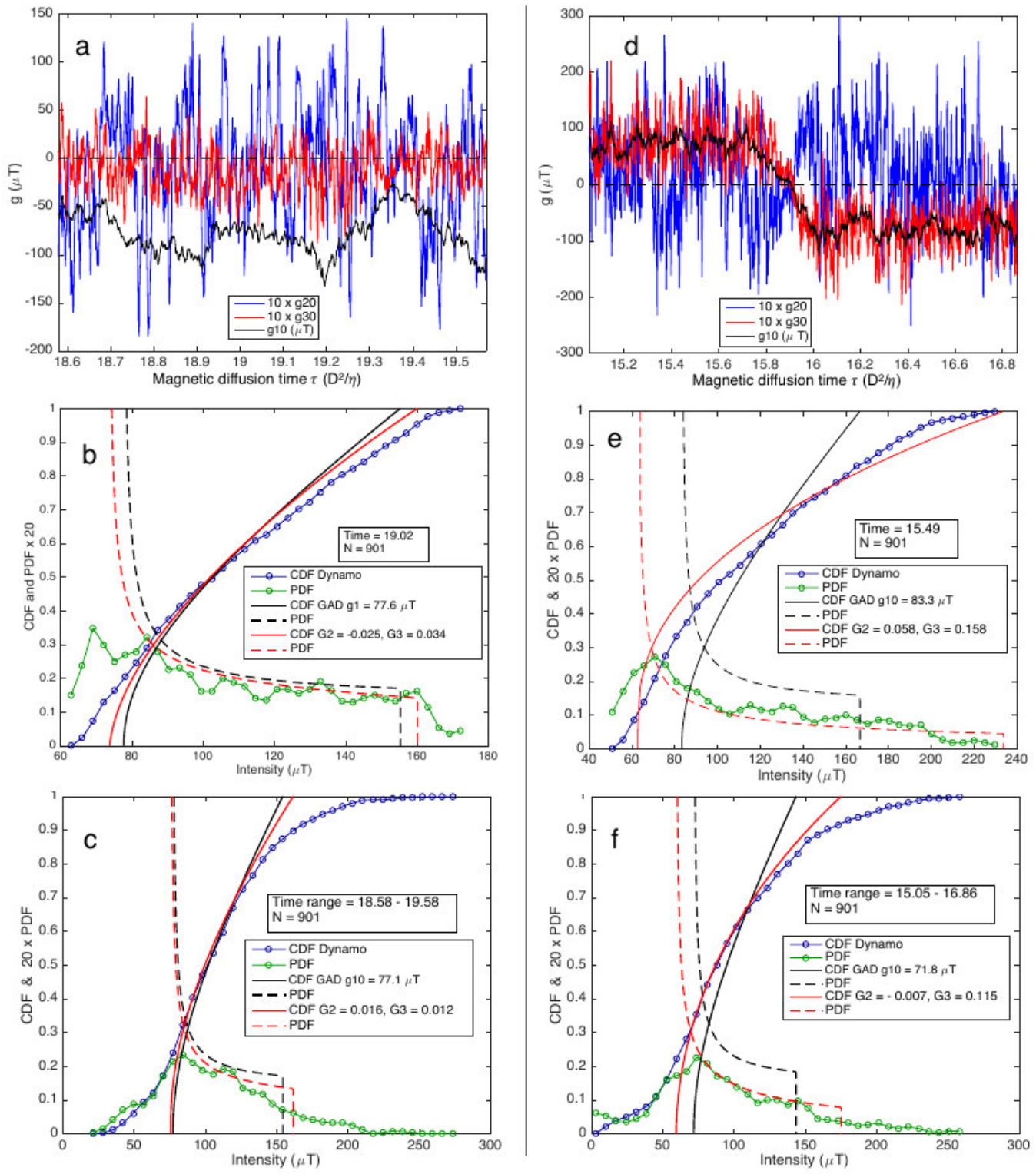

Fig. 4. 

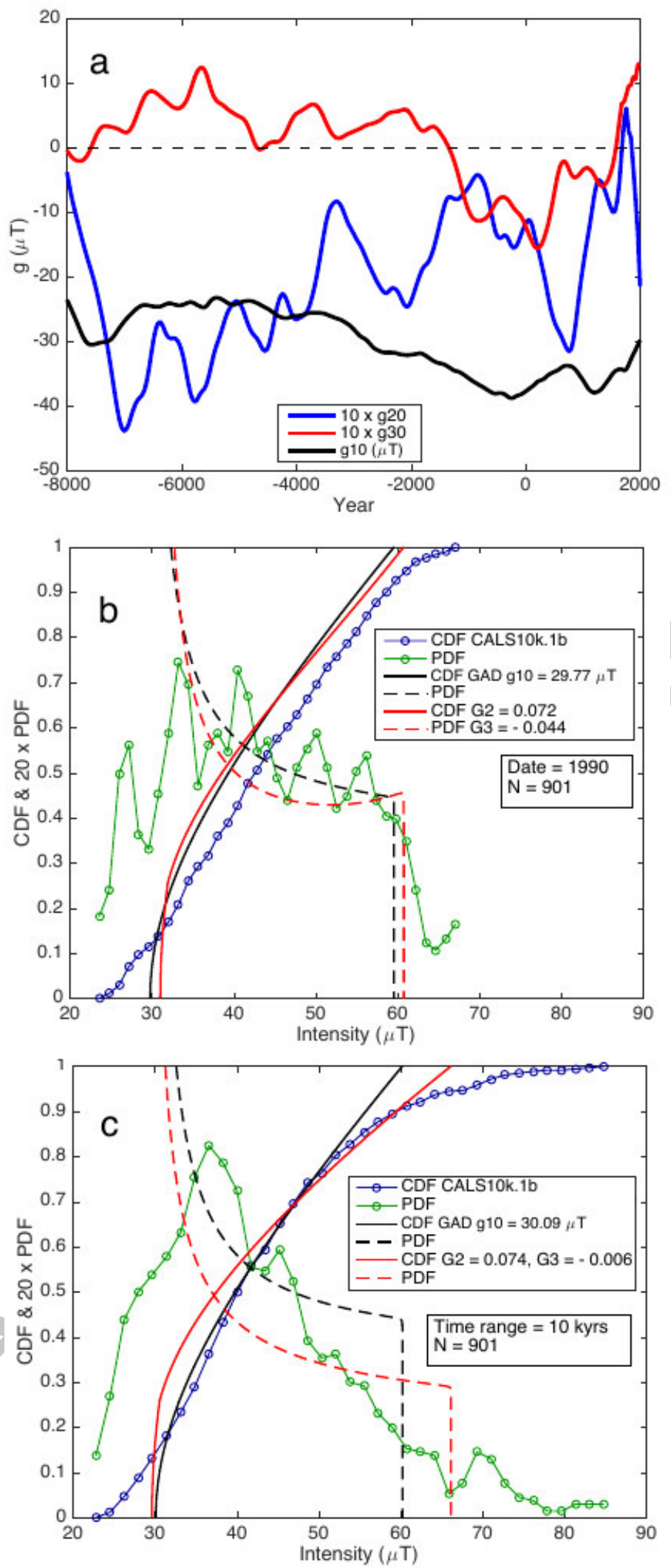

Fig. 5. 


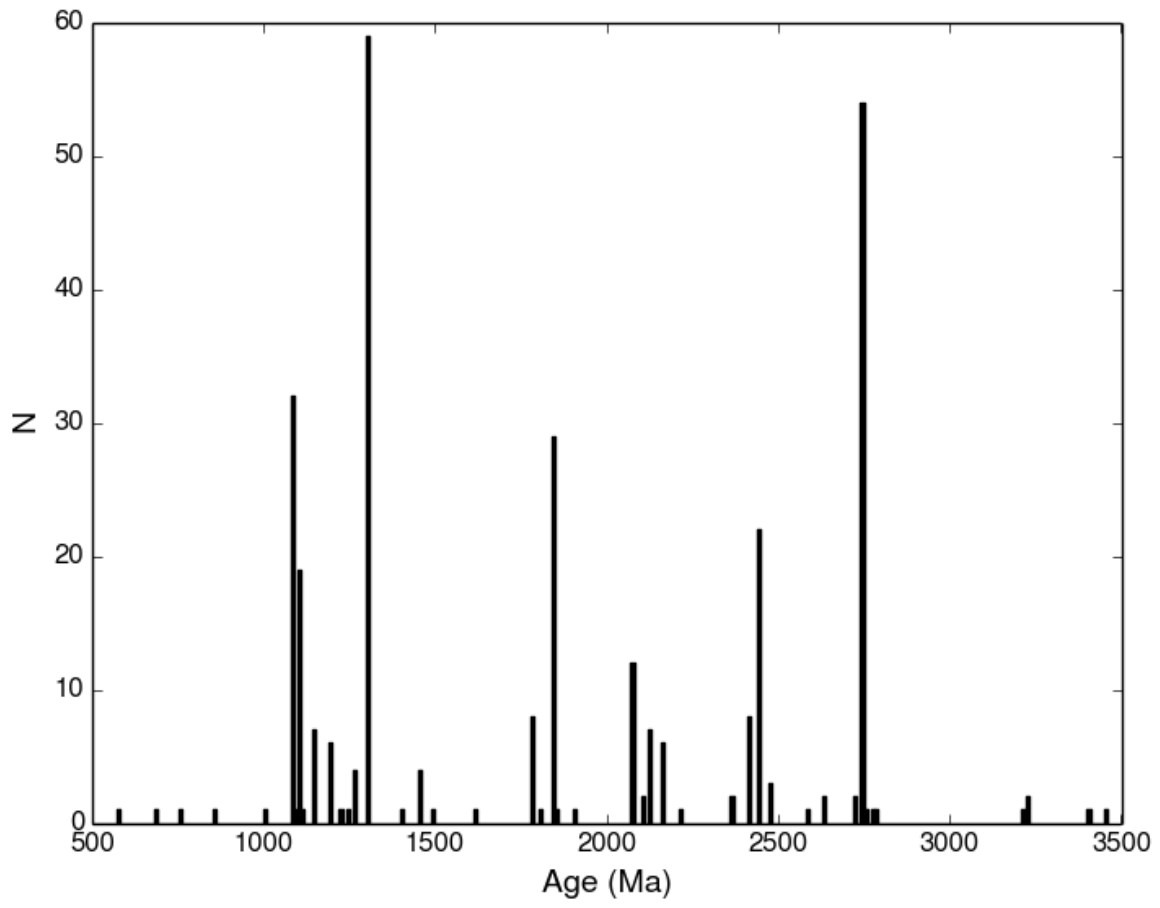

Fig. 6. 


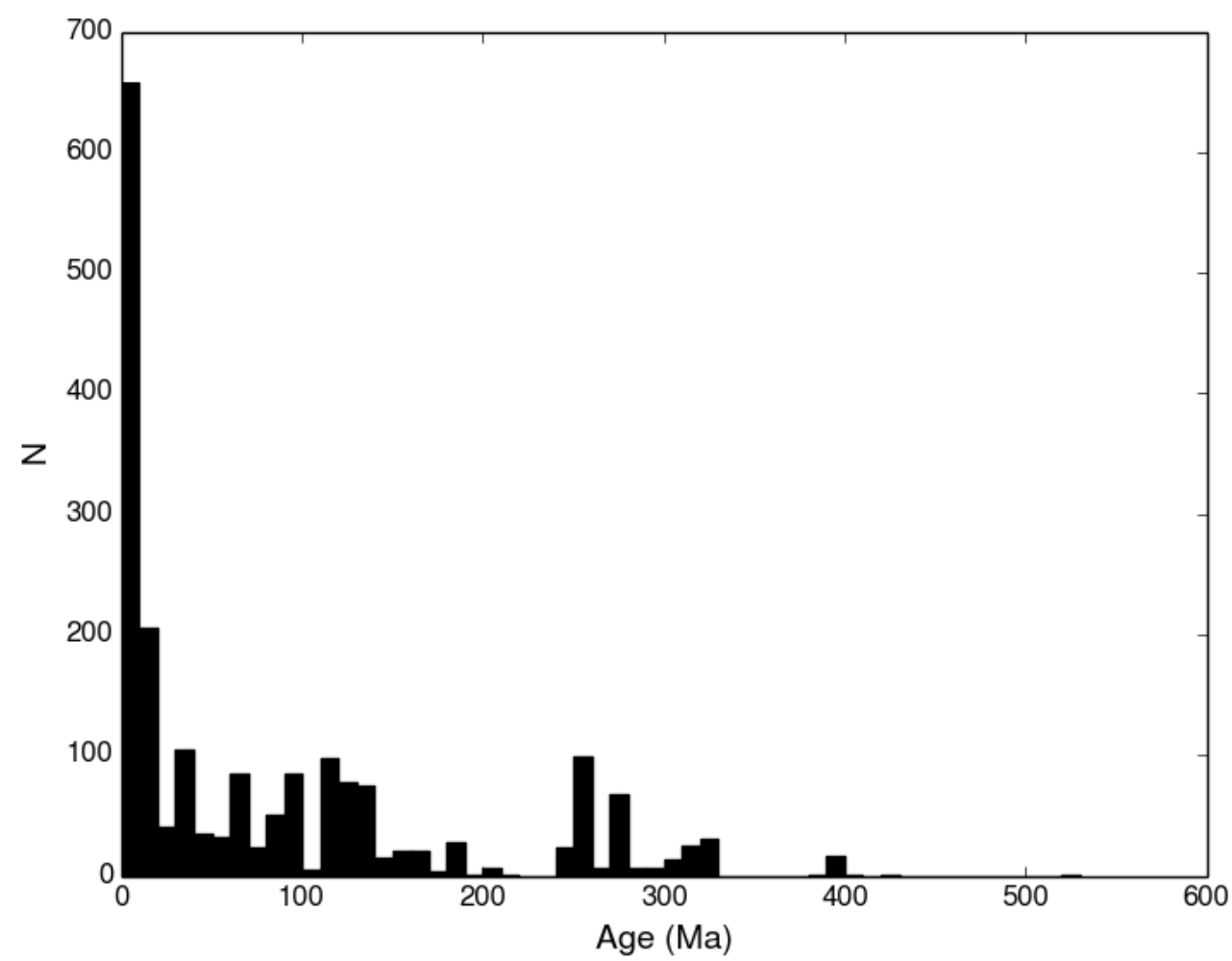

Fig. 7. 


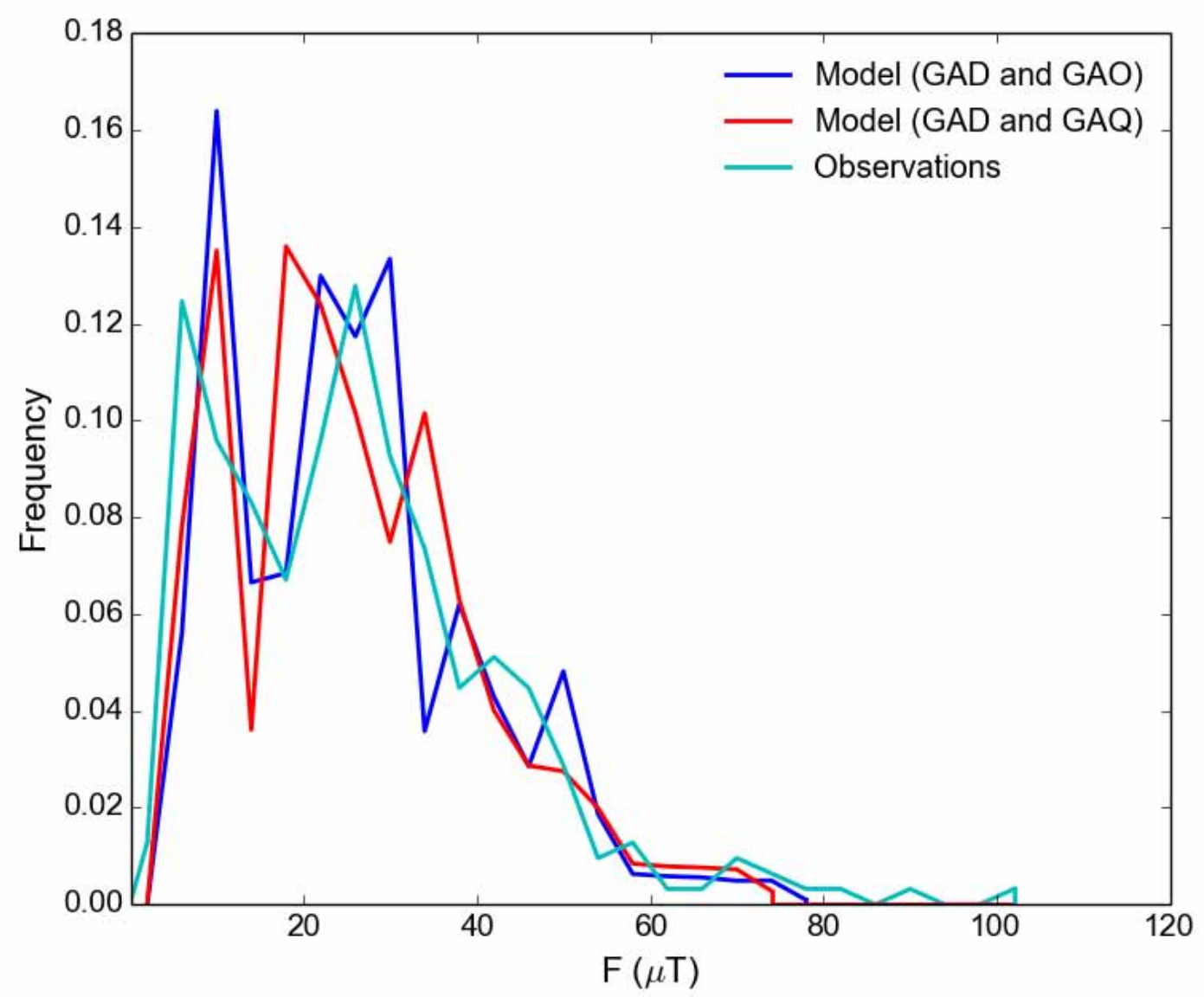

Fig. 8. 


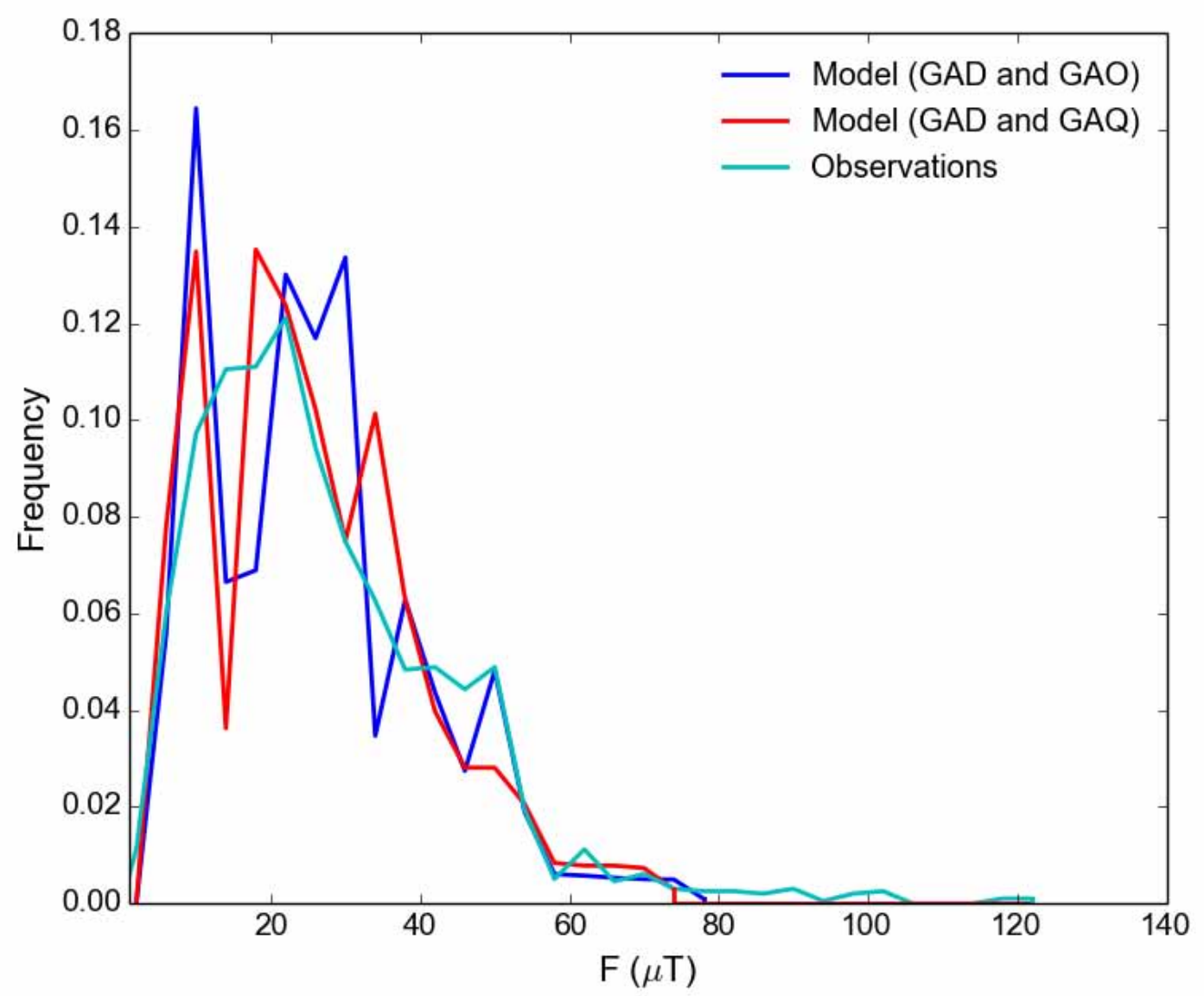

Fig. 9. 


\section{Graphical abstract}
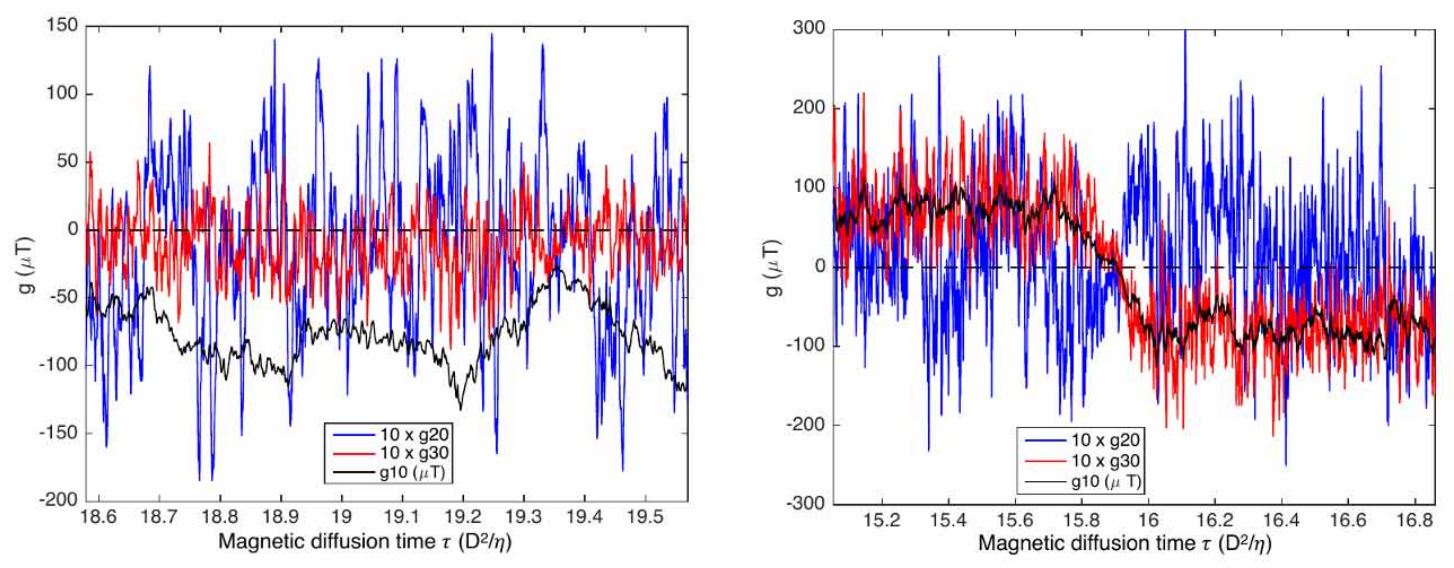